\title{
The effect of network technology on education
}

\author{
Anton J. Knierzinger \\ Paedagogische Akademie der Dioezese Linz \\ Institut für Schule und Neue Technologie \\ Salesianumweg 3, A-4020 \\ Linz, Austria \\ Tele + 43732772666 262; FAX + 432732772666295 \\ E-mail: Kna@mail.padl.ac.at \\ www.padl.ac.at/pers/kna/kna.htm
}

\begin{abstract}
Worldwide a rapidly increasing number of schools is connected to the Internet, which is a way of supporting teachers, students and school administrators.

Although many teachers have great expectations in regard to this medium in terms of new didactic possibilities, many telecommunication projects with schools are mostly dealing with the technical infrastructure. Based on the results and experiences made in the Upper Austrian school-net 'Education Highway' project the following questions will be discussed: What are the wishes and expectations of teachers concerning networks in schools? Do we meet the needs of schools by doing Internet projects with them? What results can we expect if schools are connected to a network? What are the MUSTs which make a network project for schools successful?
\end{abstract}

Keywords

Telecommunications, distance learning, Internet

\section{INTRODUCTION}

We are now watching the transformation from the industrial to the information society. Industrial production in the world is rapidly changing. Many jobs in traditional areas are no longer necessary and new jobs are created, especially in the media sector and in media-related businesses. 
But it is not only our work which is changing. New media are impacting the daily life of nearly everyone. The entertainment industry offers new techniques every year. Audio-visual media, communication technology and data processing are combined to a hyper-technique which is present all day every day.

Only learning in schools is still functioning nearly the way it did in the last century. Students still have to come to school, listen to the teacher and read the textbooks. The learning of students is still mostly controlled from outside. They cannot choose the place, time or even parts of the content they are taught, especially in vocational training where new methods and media are rarely used. Sometimes the use of new technology is added to traditional methods of teaching and learning, but this is not the revolution which we face in so many other areas. It is an interesting question why school is so resistant to change.

Looking back to the history of the past centuries we see that not every change of a paradigm in technology had great influence on the culture of learning. For example, the invention of the steam engine created a revolution in industry but it had no influence in schools, universities or other training institutions. Other inventions had a great influence on learning and teaching methods. The invention of printing books brought about the reading society of the last century, the invention of TV deleted it. What we see today is that not every technological invention has had a great influence on learning methods but every discontinuity in the media paradigm has made a difference.

Currently the development of the new digital Information and Communication Technology (NICT) is undoubtedly a radical change of the media paradigm. Therefore it will introduce a radical change in education. There are several reasons why we don't see the effects now, even if the technology is present.

The development in school is there, but it is very slow. It needs a critical mass to introduce radical changes in such a traditional system as the school. Even if many teachers are using technology today, it has not affected the overall picture of the school system.

Changes often need pressure from outside to take place. Now there is only little push from society to schools to use NICT. During the first phase of the introduction of a new technology we usually try to use it to solve conventional problems more efficiently. This is done now in schools with NICT and this is not very effective. In the next step a technology is used to solve new questions which have not been seen before.

The effects of networking technology on education will not only help us to solve known problems. Network technology in education will lead us to new challenges. It is my opinion that the effects on school systems of NICT will be evident when we stop integrating them into the established school system and when we are willing to adapt the school system to this new medium. 

AUSTRIA

\subsection{History}

Our institute has been involved in telecommunication projects for schools since 1989. In the first phase of our project we established a local network for schools. As Austria has one of the highest telephone rates in Europe only schools and teachers of Linz and the surrounding area could take part. The second phase brought Internet connectivity and 50 schools were chosen to be integrated into the test, with student access featured in this phase of the project.

On November 181996 the Landeshauptmann (Governor) of our Bundesland (Province) announced phase three of the project - the expansion of the project to all schools in Upper Austria - and the funding was agreed upon. Our institute is responsible for the development of the project, for support to schools and for the provision of content. The technical infrastructure is under the responsibility of three companies.

\subsection{Goals of the project}

The main goals for us as the developers were defined as following:

- The 'Education Highway' should be a network that links all schools of all types in Upper Austria. Even elementary schools should have access to the network. It should serve administrative as well as educational needs.

- A full and unlimited access to the Internet should be possible.

- A high level of security is necessary, especially for administrative use.

- Not more then $40 \%$ of the overall sum of investment should go into technical infrastructure. The rest should be dedicated to fund and support projects and provide for the content of importance to Upper Austrian teachers.

- As teachers in our country spend many of their working hours at home, free access to the 'Education Highway' network from the teachers' homes should be possible.

\subsection{Implementation}

The 'Education Highway' networks consist of nine Points of Presence (POPs). Teachers can link into the POPs schools either by telephone lines, ISDN or via leased lines. To avoid too much traffic on the net in every POP you will find a proxy server. All POPs are connected to the central services in our institute and to a high band connection to the Austrian School Network (ASN). ASN is a project of the Austrian Ministry of Education and serves local initiatives in the different provinces of Austria as an Internet backbone provider. Figure 1 shows the configuration for the 'Education Highway Upper Austria and the POP-toteacher/school.

You can consider the 'Education Highway' as a special type of intranet. For example, we are using an internal IP address scheme. The connection to the 
Internet runs over a firewall. That allows us to implement special security features as well as to protect schools from content which offends the Austrian laws. We think that it is not possible to react to educational problems with technical solutions and therefore we are very cautious not be seen as a censor for schools. On the other hand many parents and teachers who are afraid that students might be influenced by unsuitable information should see that efforts in this direction are undertaken.

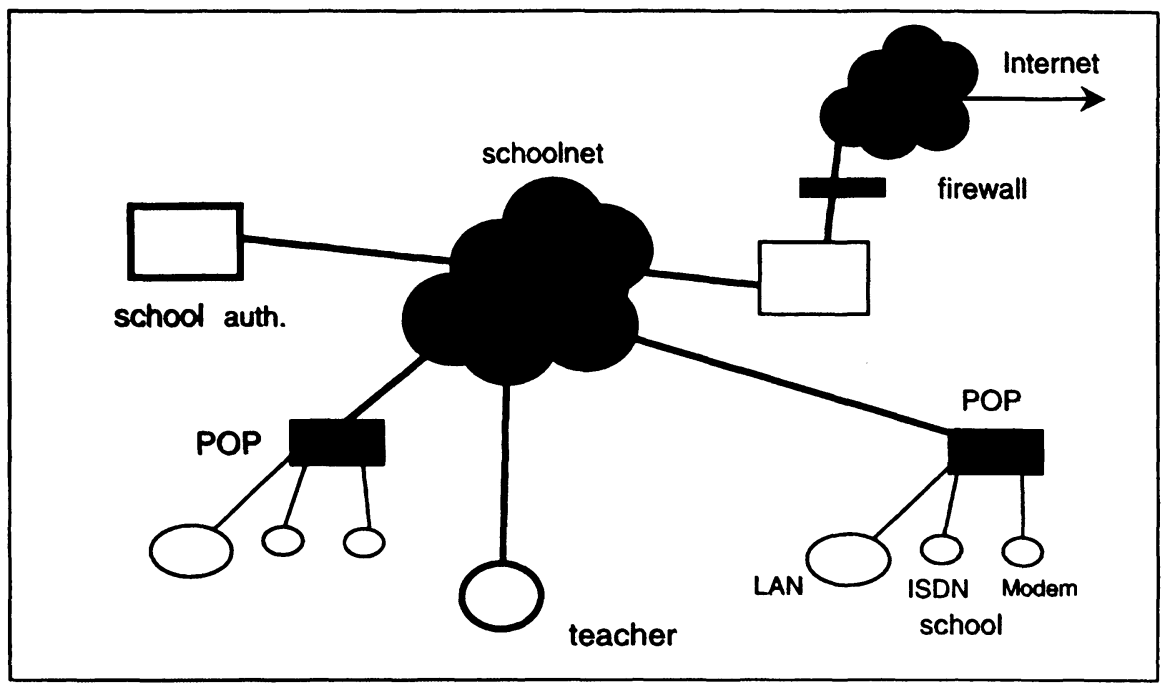

Figure 1 'Education Highway' connections.

\section{WISHES AND EXPECTATIONS}

\section{1 challenges for our educational system}

The implementation of a school network is far more then building a technical infrastructure. It is a challenge for the entire school system and therefore it should be measured by the current main goals for education. The goals might differ from country to country and should be adapted to the social and economical situation. For developed countries with a mid-European cultural background I see the following challenges for education (European Commission DGXXII, DGV).

\section{Individualization of learning}

The demands of individuals towards school and other educational institutions are much different than former times. Especially vocational training requires a better adaptation to individual needs. The whole education system is moving towards a better support of individual abilities and self-directed learning plays a much bigger role than in the past. 


\section{Lifelong learning}

The need for lifelong learning in our rapidly changing world requires new strategies which can hardly be done by the traditional learning and teaching methods.

\section{Efficiency of learning}

Schools are under the close watch of society because education in every country requires a large portion of the budget. On the other hand, the measurement of success uses more and more the methods used in measuring the economy. We have to be very careful that the economical aspects of the school system will not become the most important factors in evaluation. But facing big restrictions in our budgets we cannot ignore the fact that the efficiency of learning and training is an important issue.

In addition, school as the most important institution for learning in our society now has many competitors. Commercial educational institutions are marketing their services and are willing to use new technologies. Audio- and visual-media show how NICT can be used for learning purposes.

The use of networks in schools can bring about many benefits and can help to meet the challenges posed by external-to-the-school resources.

\subsection{Educational benefits}

During the work with networks in schools in the last seven years we discovered many possible educational benefits by using network technology. They are include a desire to raise the desire for communication.

\section{Raise the desire for communication}

Schools in Austria up to now have had a low level of communication among themselves. Neither cooperation in projects nor communication between teachers to share their experiences has been very common until now. We consider network technology as a vehicle to raise the desire for communication and cooperation.

This might effect communication:

- between schools because schools can use network technology as a medium to carry out common projects. E-mail for communication and web technology for documentation offer new possibilities for cooperation. Trans-national projects often have not been possible up to now;

- between school and society because the easy access to information from outside and the possibility for a school to publish their ideas (e.g. via a school webserver) improves the communication between school and society;

- between teachers since our experiences show that readiness for communication between teachers is much higher in an electronic environment than without.

This will effect the efficiency of teaching and improves the quality of education.

The World Wide Web (WWW) is a service which originally was designed to improve the communication between high energy physicists and has become an educational forum for communication and information (Hobbs and Taylor, 1996). 


\section{Changes the nature of learning}

Network technology introduces a big change in the nature of teaching and learning Schulz-Zander, 1997). Learning and teaching with networks will be more:

- project-oriented;

- problem-oriented;

- activity-oriented;

- open-minded;

- holistic (Weber, 1996).

Therefore the use of ICT in schools can be seen as a vehicle for the professional development of the whole school system, its content and its methodology.

\section{Improves important personal qualifications of students}

Many studies conducted around the world show that the use of ICT improves important personal qualifications of students - media competence, ability for problem solving and learning competencies in general. Therefore the use of network technology can be seen as a factor to prevent school failure.

\section{Improves professional qualifications of teachers}

The use of ICT has also greatly influences the professional qualifications of teachers. The personally-controlled access to information reduces reliance on textbooks and introduces more self-direction of the teaching process. Sharing of experiences between teachers and the exchange of materials for classroom teaching improves the quality of teaching in general.

\section{Intercultural approach}

The exchange of information between schools in different countries is also improved by network technology. Communication is now very quick and this leads to many joint projects done by schools which are far away from each other.

Access to information sources in other countries allows students of different cultures and countries to compare and exchange their opinions on a certain topic. This will lead to a better understanding of different cultures.

Improves the learning of children with special needs

There are many possibilities for how network technology can improve the learning situation for children with special needs. Communication among blind, deaf and dumb students is now possible (Cohen, 1994).

\subsection{Organizational benefits}

School administration is also expecting great benefits from the implementation of network technology. For example, improvements can be found in communication between school and administration on higher level; more information for headmasters can be easily exchange and data transfer between school and administration is much easier. 
During our studies in the last two years, since the system was established for 50 schools, we identified four factors which are very important for the success of a school network. We consider them to be mission critical factors - meaning that the absence any one of them can bring failure to the entire project.

\subsection{Time and motivation}

\section{Time}

The design of a school network must include the time factor. There must be time reserved in the curriculum for the integration of network technology. Teachers and students need time to develop their abilities to cope with technical problems. There must be enough time for teacher training which allows teachers to reach a level of competence to master the technical issues and to adapt their teaching methods to the new medium.

\section{Motivation}

Many teachers in our project are claiming a lack of motivation to use the network in classroom. There are many reasons. Teachers who don't know the creative potential of ICT are not motivated to use it. Teachers who use ICT often claim that their efforts are not respected.

But there are many sources of motivation which can be identified. On one hand, the teachers themselves can take care of their own motivation and can try to motivate each other by cooperation. On the other hand, headmasters, schooladministrators and parents can be a perfect source of motivation. Success stories which tell about successful projects and which are distributed to other teachers are one of the best ways to motivate.

What we need is the readiness of the whole school system to introduce ICT, not only a few volunteers fighting a lonely battle.

\section{2 Instruction and advice}

\section{Instruction}

The introduction of ICT must be accompanied by in-service and pre-service teacher training. This must cover the following three areas:

- technical instruction must enable the teacher to work with the technical infrastructure provided by the school;

- technical instruction is not enough - teachers need also advice on how the new technologies can help them to make their teaching better, more attractive and more efficient (Van Lück, 1997);

- many teachers become frightened when they realize that the process of using NICTs will lead to a complete change of the role of teacher and learner. Teacher training in NICT, and especially in network technology, must always include help with how to cope with the situation. 
Sources of advice

There are different sources of advice. It can come from fellow teachers, advice centers run by the school administration or through teacher training activities. In many cases, it has turned out, students can perfectly act as advisors for their teachers.

\section{Evaluation and research}

A culture of documentation and evaluation of projects must be developed, and this will produce success stories which will stand at the beginning of new successful projects.

\subsection{Equipment and content}

Equipment is necessary but is it not the dominating factor of a network project in schools. The use of a network often requires only technical functions which can be done by IT on a low technical level. Services such as electronic mail or text-based information services can also be used when high-level technology is not available.

For a schoolnet it is necessary to take care of the development and provision of content which is interesting for the target groups of the certain project. We always hear complaints about the USA's domination of the Internet and comments that there is no information in our native language available. At the moment this domination is a fact but in the case of digital networks this effect is not technologybut content-based. That means if we do not find enough information in our language, reflecting our culture and tradition on the web, it is undoubtedly our fault.

And as every country and culture has to take care of an adequate presence on the woldwide network, it is the duty of the school system to provide useful local information for the teachers. As content providers we see the 'Education Highway' as an umbrella project which, at the end, should encourage and support many local initiatives undertaken by schools, teacher training initiatives, companies and other organizations.

\subsection{Local network with worldwide connections}

The 'Education Highway' is a local network with worldwide connections. We think that 'surfing the web' has only a few pedagogical benefits. On the other hand, a school network without worldwide connections also only of little use (Van Lück, 1997). We face many problems when we offer schools access to a worldwide network and they can only be solved through a cooperation by network provider, school administration, teachers and parents. Among many other problems we see:

- the use of English and other foreign languages excludes a certain percentage of our students from the use of the majority of the existing information sources;

- different cultures and different laws in many countries result in the availability of material which might offend the children;

- technical progress in network technology is very fast and schools have difficulties keeping up with that progress; 
- the nature of the Internet does not correspond with the nature of the school system - this causes problems, especially for the use of ICT in school administration.

Based on the experiences of several years' worth of telecommunication projects for schools I would say that the following recommendations are helpful for the design of a school network:

- Divide your overall budget into three equal parts and spend the same amount of money for technical infrastructure, for content provision - including support for projects - and for training and advice.

- Look for the enrichment of teaching and learning, and not for a substitution of existing methods (Tinsley, 1994).

- Try to show that your ICT activities are meeting the basic needs of the students. In Austria these might be the following questions: 'How can I be better employable?' or 'Does this technology help to solve our global problems?'

And at the end it is necessary to find a new pedagogical vision for schools in the world if schools want to keep their leading role in educating our society.

\section{REFERENCES}

Cohen, R., Pincemin, J. andTuillier, C. (1994) International communication as means to fight against school failure, in Telematics in Education: The European Case. (eds. W. Veem, B. Collis, P. de Vries and F. Vogelzang), Academic Book Centre, De Lier, the Netherlands.

European Commission DG XXII, DG V. (1996) Teaching and learning - Towards the learning society. European Commission DG XXII, DG V. Office for the Official Publications of the European Commission, Brussels, Belgium.

Hobbs, D..J. and Taylor, R.J. (1996) The impact of education of the World Wide Web, in Maurer Hermann, WebNET 96 - Proceedings of the World Conference of the Web Society. Association of the Advancement of Computing in Education, Charlottesville, VA.

Schulz-Zander, R. (1997) Lernen in netzen. Computer und Unterricht, 25, Erhard Friedrich Verlag, Seelze, Germany.

Tinsley, D. (1994) Tele-learning in Secondary Education, in Guidelines for Good Practice (ed. T.J. van Weert), IFIP Working Group 3.1, Geneva.

Van Lück, W. (1997) Schulen ans Netz - Warum eigentlich? Computer und Unterricht, 25, Erhard Friedrich Verlag, Seelze, Germany.

Weber, W. (1996) Vorschlag für die pädagogische Konzeption des NRW Bildungsservers. Landesinstitut für Schule und Weiterbildung, Soest, Germany 
After studying Physics and Mathematics at the University of Vienna, Anton J. Knierzinger worked for eight years as a school teacher in Linz. In 1996 he moved to the Paedagogische Akademie der Diocese Linz, where he is now heading the Institute for School and New Technology (IST). The main focus of his work is teacher training, distance learning and the introduction of IT into elementary education. He chairs the International Federation for Information Processing (IFIP) Working Group on IT in Elementary Education, WG 3.5. 